the Malay (judging by the skeletons in the College Museum) agree with the negro rather than with some other branches of the so-called Mongoloid races, as the Eskimo and the Samoyede. But this is a subject for further observation rather than hasty generalisation.

The difference between the pelvis of the African negro and that of the European has been pointed out by Vrolik and others. It consists mainly in the increase of the antero-posterior diameter as compared with the transverse, expressed by the pelvic index, or ratio between these diameters, the latter being taken as Ioo. In the European male the average index is 80 , in negroes, according to various observers, from 90 to Ioo. As in the proportions of the limbs, many of the Mongoloid races conform in the characters of the pelvis rather with the negro than with the European.

In the cranial characters the distinctions between the negro and the white races are strongly marked. The average capacity of the cerebral cavity is undoubtedly smaller in the former, even in individuals of approximately the same height. It is, however, considerably higher than in the Australian. The difference between the average capacity of English and negro crania in the College Museum is 123 cubic centimetres, between the latter and the Australian 8 o c.c. Broca's totally independent measurements of skulls at Paris give a difference in the former case (Parisians being substituted for English) of 128 c.c., and in the latter of 83 c.c., so that the results are substantially identical. The general form of the cranium is expressed by the cephalic or latitudinal index, or relation of breadth to length, the latter taken as Ioo. The average index of forty-two negroes of various tribes in the College Museum is $73^{\circ} 6$. Of these more than half are between 70 and 75 , or dolichosephalic; less than half are above 75 , or mesaticephalic; but very few are either below 70 or above 80. The average index of eighty-five negroes from the West Coast of Africa, measured by Broca, is $73^{\circ} 4$, and of fiftythree from East Africa, measured by Lederle, is $73^{\circ} 9$. These remarkable agreements with our own measurements show that between 73 an 74 may be fairly taken as a general average of the cephalic index of the African negro, and that he belongs, therefore, to the moderately dolichocephalic races. The height, measured from the basion to the bregma, is almost identical with the breadth, the average of the forty-two College specimens giving 73.5 . The negro skull in these proportions differs greatly from that of the Fiji Islanders previously described. Differences in the position of the foramen magnum, in the angle formed by its plane, with the horizontal of the skull, and in the various facial angles, which have been pointed out as characterising the negro skull as compared with that of the European, can only be explained by means of diagrams. The facial characters are generally eminently characteristic. The forehead, though narrow, is not retreating. The glabella and supra-orbital ridges are sometimes well developed, but more usually this region is smooth and flat. The orbits have a moderate index, $85^{\circ} 5$ (Broca), or 86.3 according to measurements of the College collection. The nose is distinctively platyrhine, the average index being 55 or 56 . The nasal bones are small and flat, their external surfaces directed forwards, the two meeting in front at a very open angle, instead of a narrow one as in Europeans. The lower margin of the nasal aperture is usually rounded off instead of sharp and strongly defined. Equally characteristic is the pro onathism, which is very rarely absent. The measurement from the basion to the middle of the alveolar border is greater than that from the basion to the nasofrontal suture, whereas in Europeans the reverse is almost always the case.

The teeth are regular, well developed, and generally free from caries. The third molars (wisdom teeth) appear to be always in their place before the closure of the basilar suture, whereas among Europeans they are often much later in coming into place. The size of the teeth varies in different races, but hitherto no accurate measurements have been made to express their difference. The length of the molar series, in a straight line between the anterior edge of the first premolar and the posterior edge of the third molar, may be conveniently used to indicate the size of the teeth, and called $d$. This may be compared with the length of the cranio-facial axis, or basi-nasal length (B N), and a dental index formed from $\frac{d \times 100}{\mathrm{~B} \mathrm{~N}}$. This will give at all events a fair approximation to the relative size of the teeth compared with the skull, as the length B N is one of the least liable to variation of any in the cranium. Unfortunately for the investigation, in a large proportion of the crania in Museums the teeth are wholly or partially lost, and a larger number of specimens must be measured than are at present available. The following indices (which must be regarded as provisional) are however of considerable interest. In the first place it must be observed that the teeth of women, though smaller absolutely, are larger relatively to the cranio-facial axis than those of men. For instance, in Europeans the dental index of males is $40^{\circ} 5$, of females $42^{\circ} 0$. In Australians the disproportion is greater still, being $45 \%$ for the males, and 48.4 for the females examined. In the following table males only will be included. Europeans 40.5, Ancient Egyptians $40^{\circ} 8$, Hindoos $41^{\circ} 2$, American Indians $42^{\circ} 5$, Chinese $43^{\circ} 8$, African Negroes 43'9, Andamanese $44^{\circ}$, Fijians $45^{\circ} 4$, Australians $45^{\circ} 7$. It will thus be seen that in the size of the molar teeth the negroes hold an intermediate position between Europeans and Australians, but approaching nearer to the latter. The actual average length of the molar series in European males is 40.8 millimetres, in Africans $45^{\circ} 4$, in Australians 46. The anthropoid apes give a higher index than that of any of the races of man.

(To be continued.)

\section{ON SYSTEMATIC SUN-SPOT PERIODICITY}

$A \mathrm{~T}$ the present moment, when a good deal of attention $A$ is being directed to sun-spots and their possible influences, it may not be amiss to discuss the question of their systematic periodicity.

We have to ask ourselves whether we can by a limited application of labour so disentangle the apparently complicated and capricious phenomena of sun-spots as to exhibit certain well-defined recurring periods, the superposition of which upon each other may ultimately explain the march of these phenomena. It will be apparent that such an analysis of the past is the first and indispensable step towards any prediction for the future. I will now bring before the readers of NATURE the first results of an attempt of this kind. As the subject will be more fully discussed in another place, I will in the meantime mainly exhibit the results obtained, referring as briefly as may be to the method used in procuring them. The method is that which (in conjunction with Mr. Dodgson) I have already brought before the notice of the Solar Physics Committee and of the Royal Society. It has been applied to thirty-six years of sun-spot observations, beginning with 1832 and ending with 1867 . The first portion of these has been derived from the records of Hofrath Schwabe, the second from those of Carrington, while the latter portion has been derived from De la Rue's Kew series. My first object has been to ascertain to what extent these records exhibit indications of certain systematic inequalities having periods not far differing from twenty-four days. I will limit the present communication wholly to this issue.

These thirty-six years have been split up into three series of twelve years each, and treated after the manner 


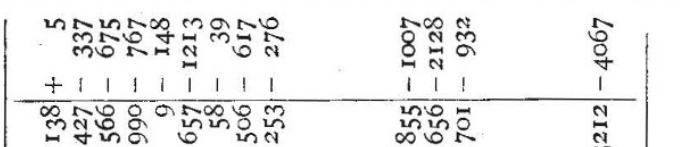

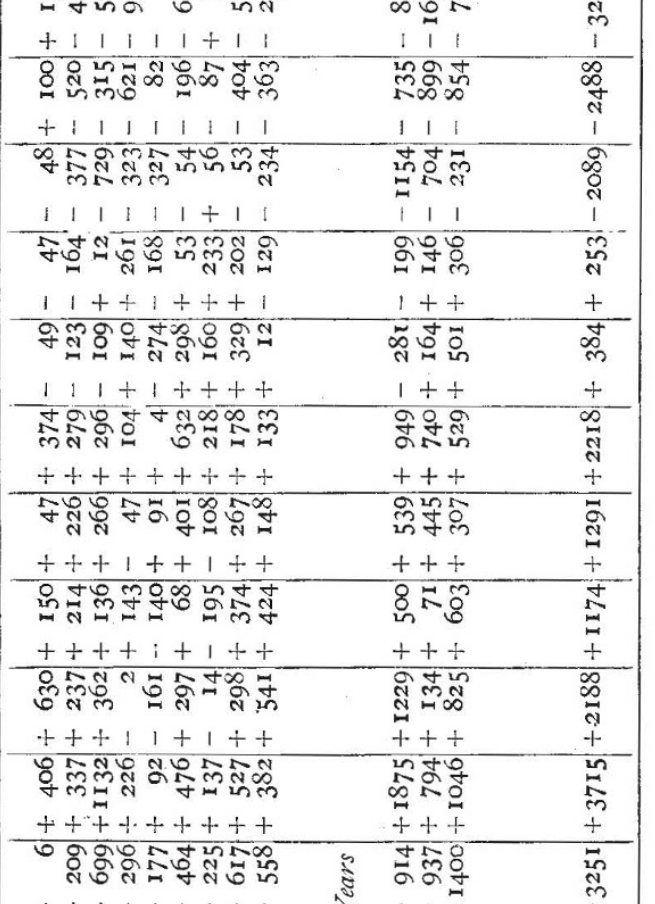

\begin{tabular}{|c|c|}
\hline$++++1+1++$ & ++1 \\
\hline 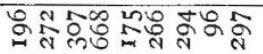 & 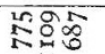 \\
\hline$t+t+++1111$ & ++1 \\
\hline 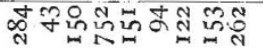 & 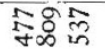 \\
\hline$+++++1 \quad 1111$ & ++1 \\
\hline
\end{tabular}

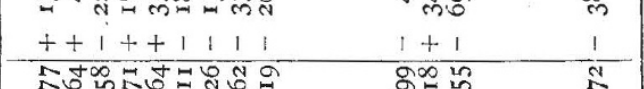

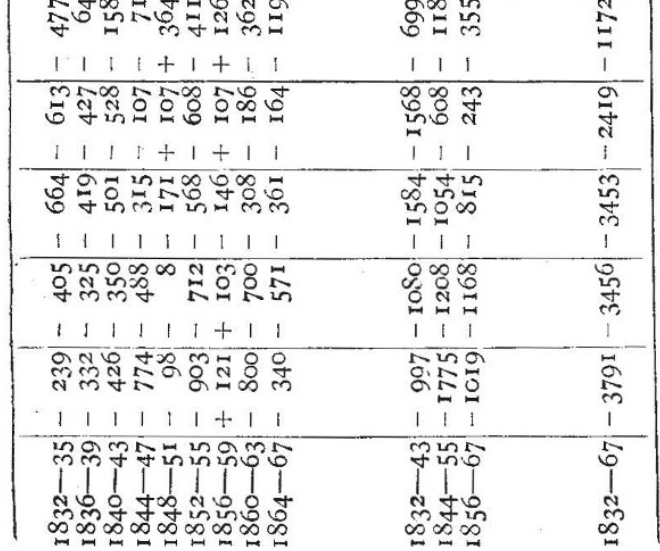

\begin{tabular}{|c|c|}
\hline 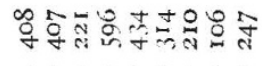 & 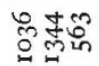 \\
\hline 111111111 & 111 \\
\hline 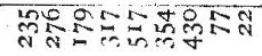 & סूक्ष \\
\hline $11: \vdots 111$ & 131 \\
\hline 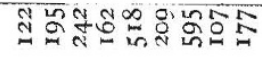 & 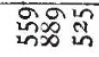 \\
\hline $\begin{array}{lll}11 & 11+\end{array}$ & 111 \\
\hline 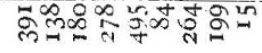 & 象㐬 \\
\hline $11: \quad 111+$ & $\begin{array}{lll}1 & 1 & 1 \\
0 & 0 & 1\end{array}$ \\
\hline 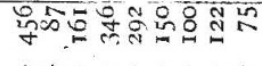 & 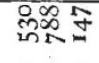 \\
\hline
\end{tabular}

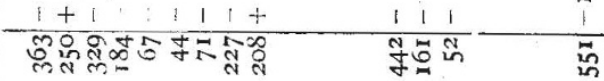

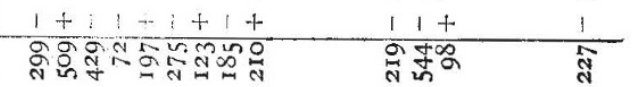

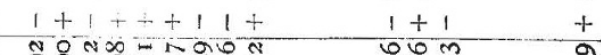

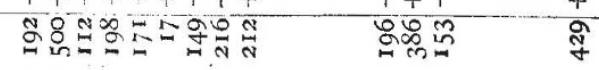

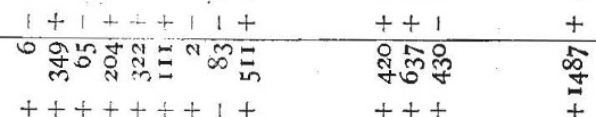

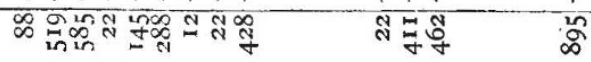

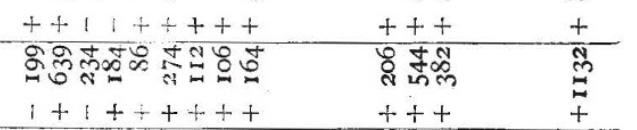

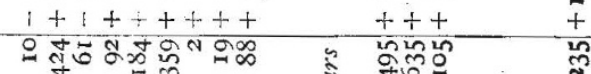


which is fully described in the communications already alluded to. By this means the positions of the various inequalities around twenty-four days have been indicated on the time-scale. I have next taken two of these and attempted to eliminate from them the influcnce of all neighbouring inequalities, in order to sce with what success it is possible to disentangle the various periods from each other. In order to test this success I have exhibited in the tables on p. 81 the result of this elimination applied to each four years of sun-spot records, and I think it will be manifest to every one that there is such evidencc of repetition, that one cannot doubt the reality of the periods therein indicated. I have likewise begun to apply to these records Gen. Strachey's test, and with a good result so far as I have yet gone.

No kind of smoothing or equalisation has been applied, and the elimination has been carried on only to the first stage, so that more accurate determinations will probably result from a further application of labour.

\section{BALFOUR STEWART}

\section{PRIMITIVE $M A N^{1}$}

$\mathrm{I}^{\mathrm{T}}$ $T$ is a familiar fact that from time to time wrong-headed but enthusiastic persons appear in the scientific arena boldly challenging the truth of some one or other of the most firmly-established and essential doctrines of the scientific creed. Sometimes a clever investigator discovers that we moderns are all in the wrong, and that the sun after all goes round the earth; another will have it that the moon does not revolve on its axis; a third disputes the correctness of the theory of gravitation; whilst a fourth finds no difficulty whatever in squaring the circle. Such men have cropped up at intervals throughout the historical period. 'They are not without their usefulness in their generation, for they afford some little mirth, and give an opportunity sometimes to men of science to reconsider their standpoints and settle themsclves more firmly upon them. It seems uncertain whether Prof. Dawson, of McGill College, Montreal, is to bc classed with these malcontents, or whether his scientific heresies are to be explained as conforming to the general law that superstitions generally survive and even thrive in colonies long after they have dicd out in their mother country.

No greater contrast could well be conceived than is presented by the two works on Primitive Man which have just appeared, and which form the subject of the present article.

Prof. Boyd Dawkins, in accordance with the teachings set forth in his "Cave Hunting" and all other works which have procceded from bis pen, treats his subject in a thoroughly scientific and unprejudiced manner, and the results which he lays before his readers are in keeping with the conclusions now fully accepted by all anthropologists and admitted by cducated persons generally. Prof. Dawson, on the other hand, has actually written a book at this present time, the object of which is to attempt to show that mankind first made its appearance on the earth not more than 6,000 or 8 ,oco years ago. He sums up thus :"What evidence the future may bring forth I do not know, but that available at present points to the appearance of man with all his powers and properties in the Post-glacial age of geology, and not more than 6,000 to 8,000 years ago." His book is described as "an attempt to illustrate the characters and condition of prehistoric men in Europe by those of the American races." His arguments are old stagers long ago upset. Such, for example, as that because some savages, such as the Veddahs of Ceylon, who are degraded Singhalese, are degencrate, therefore

" "Early Man in Britain and His Place in the Tcrtiary Pericd." By W. Boyd Dawkins, M.A., F.R.S., \&c. (Lendcn: Macmillan and Co., r88o.) LL.D., F.R.S., \&c., McGill College, Mlontreal. (Ly Stoughton, 1880.) all savages are the degenerate offspring of highly-cultivated races. On similar grounds we might infer that because barnacles and ascidians can be shown to be degenerate animals, therefore all lower animals have undergone "degeneration," to use Prof. Ray Lankester's term, and all monkeys are degenerate men.

The main argument of the book is however apparently that derived from the results of excavations made on the site of Montreal. On this site, as we know from Cartier's narrative, stood in 1535 the native town of Hochelaga, which was fortified, as shown in the plan of the town at the end of the third volume of Ramusio's collection of Voyages and Travcls, by means of a circular triple wall of wooden beams, the outcr of which were inclined to meet one another at the summit. The native town, its buts and walls, naturally disappeared within a century, and all that now remains of it are the implements and bones which are to be dug out on its site, and of which Prof. Dawson gives an interesting account. There are tobacco pipes of various kinds, stone weapons, pottery, and bones of animals and men. If it had not been for Cartier's visit and published narrative antiquarians might have ascribed a very early date to these remains, argues the author, therefore in all cases where a very early date has been assigned to human remains of the palæolithic age in Europe a similar error has been committed. We cannot follow Prof. Dawson through his attempts to contort the data of modern science into accordance with Chaldxan cosmogonies and mythology as familiar to us in Jewish dress. He gravely refers the remains found at the camping ground at Solutre which, according to $M$. de Mortillet, mark a special epoch (the Solutrian) in the palæolithic age, to the antedilurian epoch, and reminds us how Jabal, before the flood, according to Genesis, initiated the nomadic mode of life, suggesting that the old inhabitants of Solutre who hunted the mammoth, the cave lion and cave bear, were Jabalites. It is delightful to find how beautifully everything fits into its place when freely interpreted by Prof. Dawson. The results of his ethnographical and antiquarian researches appear to be more or less summed up in the biblical text, "God shall enlarge Japhet, and he shall dwell in the tents of Shem, and Canaan shall be his servant." This means, as he aptly explains, that the Aryan or Japetic races were to be endowed with "the higher control of the physical forces and the greater power of expansion and propagandism," in short, amongst other exploits, to exterminate the Redskins and colonise America; whilst the Semitic races were to receive historical and spiritual revelations, and Canaan in the text represents unprogressive humanity generally.

Prof. Dawson's intimate acquaintance with the details of prehistoric religion is most startling. He holds up the faith of palacolithic, or palaocosmic, man, as be prefers to call him, as a warning and a pattern to the degraded Ritualist, at whom he cannot help having a dig even with palæolithic weapons, being evidently a staunch l'rotestant. He slays evolutionists with the same thrust. It is an unexpected honour for them to die in such company. No coubt the association is meant to give the Ritualists the hardest dig. He wishes "distinctly to affirm that the prehistoric religions, and what we call heathenism or aninism of untaught tribes, were nearer to God and truth than are either the ritualisms and idolatrics or the materialistic scepticisms of more civilised times, when men, 'professing themselves to be wise, become fools.' " Till we read this passage it seemed to us that Prof. Dawson professed himself throughout his book to be very wise incleed, but of course he cannot have intended to pose in that attitude. The chapter concludes by calling on "all men cverywhere to repent," and so we do heartily of having followed so far Prof. Dawson's, shall we call it "wisdom"?

We turn with relief to Prof. Boyd Dawkins's finc volume. It is sumptuously printed, and contains 168 